\title{
AÇÃO EDUCATIVA A PARTIR DA PEDAGOGIA EMPRESARIAL NUMA UNIVERSIDADE PARAGUAIA
}

\section{EDUCATIONAL ACTION FROM ENTREPRENEURIAL PEDAGOGY IN A PARAGUAY UNIVERSITY}

\author{
Gustavo Enrique Costa ${ }^{\mathrm{I}}$ \\ Doralice Nunes Alcantara ${ }^{\mathrm{II}}$
}

\section{RESUMO}

O presente artigo tem o objetivo de caracterizar a ação educativa, no viés da Pedagogia Empresarial realizada numa Universidade em território paraguaio, na cidade de Pedro Juan Caballero, fronteira com Ponta Porã-Brasil. A partir do Projeto de Intervenção foram realizados os seguintes procedimentos: visita técnica à Universidade; leitura do Regulamento Geral da Universidade; conhecimento e análise do sistema informático da Universidade; estudo das reais funções da Secretaria Acadêmica; análise e acompanhamento das funções dos funcionários da secretaria acadêmica; construção do Manual de Funções. Após a leitura do Regulamento foi construído o Manual sistemático e informativo como um dos suportes para as informações legais segundo os Documentos Oficiais, além disso foi realizado um Seminário a fim de possibilitar qualificação sobre a utilização do Sistema Acadêmico. Como resultados, aponta-se que o Pedagogo Empresarial é fundamental na organização, planejamento e execução de projetos no sentido de atender as necessidades da organização.

Palavras-chave: Ação Educativa. Pedagogo Empresarial. Pedro Juan Caballero.

\section{ABSTRACT}

his article aims to characterize the educational action, in the bias of Business Pedagogy held at a University in Paraguayan territory, in the city of Pedro Juan Caballero, bordering Ponta Porã - Brazil. From the Intervention Project, the following procedures were carried out: technical visit to the University; reading the General Regulations of the University; knowledge and analysis of the University's computer system; study of the real functions of the Academic Secretariat; analysis and monitoring of the functions of the staff of the academic secretariat; construction of the Function Manual. After reading the Regulation, the systematic and informative Manual was constructed as one of the supports for legal information according to the Official Documents. In addition, a Seminar was held to enable qualification on the use of the Academic System. As results, it is pointed out that the Business Pedagogo is fundamental in the organization, planning and execution of projects in order to meet the needs of the organization.

Keywords: Educational Action. Business Pedagogue. Pedro Juan Caballero

\footnotetext{
I UFMS, Campus de Ponta Porã, MS, Brasil. E-mail: gustavo.pedagogia.ufms@gmail.com

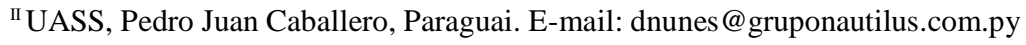




\section{INTRODUÇÃO}

O pedagogo é um profissional que deve ter um arcabouço de conhecimentos e competências para lidar com diversificadas demandas e público, ou seja, educandos e educandas em fase escolar desde a tenra idade, zero anos até a fase adulta. E também para atuar em diferentes espaços, ou seja, nas escolas, organizações, igrejas, em Organização não governamental, nos sindicatos, conselhos de pais e mestres, nas associações, em hospitais, entre outros ambientes, com intuito de contribuir com a educação das pessoas nesses diferentes contextos. Assim, a educação - não formal está presente em vários órgãos, instituições e espaços.

É importante dizer também que essa educação engloba um apanhado de práticas sociais que possibilita aprendizagem, desenvolvimento de saberes em organizações, instituições mediante uma multiplicidade de programas e projetos sociais. Assim, desenvolve projetos e ações em instituições não formal de educação, visando atender as necessidades institucionais e das pessoas que nelas convivem ou transitam.

Os projetos propostos geralmente têm intencionalidades, clareza, coerência a fim de contribuir com as demandas e necessidades que os espaços apresentam. Sabe-se, que a ação educativa em espaços nâo formais não substitui a escola, e os objetivos versam na perspectiva de contribuir com a formação social e cidadã de indivíduos em qualquer idade, etnia, sexo, nacionalidade, classe econômica.

Nesse interin a educação não - formal, humaniza, socializa, desenvolve, provoca mudança social e promove participação entre os envolvidos. Para corroborar Gohn (2014), conceitua Educação-não formal como

[...] um processo sociopolítico, cultural e pedagógico de formação para a cidadania, entendendo o político como a formação do indivíduo para interagir com o outro em sociedade. Ela designa um conjunto de práticas socioculturais de aprendizagem e produção de saberes, que envolve organizações/instituições, atividades, meios e formas variadas, assim como uma multiplicidade de programas e projetos sociais. A educação não-formal, não é nativa, ela é construída por escolhas ou sob certas condicionalidades, há intencionalidades no seu desenvolvimento, o aprendizado não é espontâneo, não é dado por características da natureza, não é algo naturalizado. $\mathrm{O}$ aprendizado gerado e compartilhado na educação não-formal não é espontâneo porque os processos que o produz têm intencionalidades e propostas (GOHN, p. 06, 2014).

Nesse viés, entende-se o quão é fundamental a educação-não formal, pois abrange um leque diversificado de conhecimentos e vivências. A Resolução CNE/CP $\mathrm{n}^{\circ} 1$, de 15 de maio de 2006, que institui as Diretrizes Curriculares Nacionais para o Curso de Graduação em Pedagogia, em seu art. 4" "IV estabelece que esse profissional pode "trabalhar, em espaços escolares e não-escolares, na promoção da aprendizagem de sujeitos em diferentes fases do desenvolvimento humano, em diversos níveis e modalidades do processo educativo".

Entre os espaços de ação educativa do trabalho pedagógico está as organizações e empresas. O pedagogo é de suma importância no âmbito empresarial, pois ele irá analisar e direcionar os funcionários e a empresa para melhorias. Nesse sentido, o trabalho desse profissional de educação pode atender demanda referente a estruturação e reestruturação de 
determinadas áreas problemáticas da empresa. Neste propósito o pedagogo, recria, reelabora, reorganiza, provoca mudança de comportamento nos funcionários e envolvidos.

No que se refere à função do pedagogo empresarial, pode-se dizer que se pauta na qualificação da equipe que desenvolve diferentes funções nas áreas da empresa, com intuito de gerar qualidade e produtividade. Cabe ressaltar que ele exerce o papel de educador dentro da empresa, faz observações cuidadosas, envolve-se, é criativo e dinâmico.

O educador ajuda o funcionário a melhorar seu potencial para que possa desempenhar a função de eficaz e coopere com o atendimento das necessidades da organização. Uma das tarefas essenciais do Pedagogo Empresarial, refere-se também ao desenvolvimento de projetos que conforme Prado (2013, p. 71)

Uma das atividades importantes do pedagogo empresarial será de colaborar na realização de projetos. A realização de um projeto implica em construir e elaborar um roteiro de trabalho desenhando e projetando as ações da empresa. Uma ação que irá ser executada vem de um projeto elaborado para se obter exatidão das técnicas abordadas de modo a garantir resultados satisfatórios em sua execução.

Por isso, no que se refere à elaboração de projetos, percebe-se que o pedagogo, necessita de um vasto leque de conhecimentos e habilidades para desenvolver projetos com metodologias, objetivos e recursos que resultem $n$ a satisfação de todos os envolvidos. Nesse contexto o pedagogo empresarial atua, com intuito de propiciar melhorias na qualidade e prestação de serviços, e com base nestes princípios, dialogamos ainda, com Gonçalves:

\begin{abstract}
Atualmente a empresa começa a abrir espaço para que este profissional possa de maneira consciente e competente, proporcionar um ambiente que se esteja solucionando problemas, elaborando projetos formulando hipóteses visando à melhoria dos processos instituindo, na empresa, garantindo a qualidade do atendimento contribuindo para a instalação da cultura institucional da formação continuada dos empregados. O pedagogo poderá atuar na empresa produzindo e difundindo conhecimento, assim, exercendo seu papel de educador (GONÇALVES, 2009, s/p.).
\end{abstract}

Em suma, o pedagogo empresarial necessita ser crítico, criativo e capaz de se adaptar as mudanças, se apresentar e desenvolver suas funções de maneira prática/teórica em cada departamento da empresa. Com essa perspectiva, o pedagogo precisa pensar numa educação que ultrapasse as exigências mercadológica, ser crítico e ter atitudes, pois será um intermediador do empregador/pessoal que fará mudanças necessárias por meio de projetos na de gestão empresarial e dos recursos humanos, com vista no favorecimento do crescimento profissional e de toda empresa.

Nesse sentido, foi elaborado um Projeto de Intervenção de Ação Educativa em Espaços Nãoescolares e desenvolvido na Universidade Autônoma San Sabastian, em Pedro Juan Caballero, no Paraguai. O desenvolvimento das ações educativas ocorreu no viés da Pedagogia Empresarial, tendo em vista que mesmo sendo uma instituição de ensino não deixa de ser uma organização, pois lida com recursos humanos e gestão de pessoas. Assim, o presente artigo tem o objetivo de relatar a experiência educativa realizada na Universidade Autônoma San Sabastian, em Pedro Juan Caballero, no Paraguai, 
no viés da Pedagogia Empresarial que possibilitou problematizar acerca da prática educativa e agregar conhecimentos inerentes ao papel do Pedagogo Empresarial.

\section{MATERIAL E MÉTODO}

Trata-se de um relato de experiência de uma ação educativa desenvolvida na Universidade Autônoma San Sabastian, em Pedro Juan Caballero, no Paraguai. Para isso, foi feita uma revisão bibliográfica para conceituar e caracterizar as atividades desenvolvidas pelo profissional de educação em espaços de organizações e empresas.

Inicialmente foi realizada uma visita técnica a instituição para levanter a demanda da mesma. Neste processo o Diretor Acadêmico, sugeriu à construção de manual de organização/função de cada departamento da instituição, especialmente, na secretaria acadêmica com suporte do Regulamento Geral da Universidade. Outra sugestão do diretor referiu a pesquisa com os acadêmicos do Curso de Medicina, com o objetivo de avaliar a prática pedagógica dos professores e ressaltou que esta pesquisa proporcionaia informações para detectar fortalezas e fragilidades do trabalho docente

Por meio disso, foi estruturado um Plano de Intervenção para ser realizado em 180 dias e que derivou na intervenção, que ocorreu na instituição e envolveu o diretor acadêmico, os funcionários dos departamentos financeiros, acadêmico e contou com a colaboração e supervisão da Assessora Geral da instituição UASS. Os resultados desta experiência foram apresentados e discutidos na seção seguinte.

\section{RESULTADOS E DISCUSSÃO}

O educador/pedagogo/profissional da educação necessita ter sua prática pautada na ética, compromisso, transparência e responsabilidade dentro de um espaço não formal de educação. Por isso, é necessário também ter assiduidade, pontualidade, comportar-se conforme as normas institucionais, respeitando as diferenças sociais, políticas, sobretudo o tempo de aprendizagem de cada sujeito que faz parte do espaço/instituição. Para explicitar a ética do pedagogo, é fundamental, citar a Resolução $\mathrm{CNE} / \mathrm{CP}^{\circ}{ }^{\circ} 1$, de 15 de maio de 2006, que institui as Diretrizes Curriculares Nacionais para o Curso de Graduação em Pedagogia, licenciatura, em seu Art. 5 "O egresso do curso de Pedagogia deverá estar apto a: I - atuar com ética e compromisso com vistas à construção de uma sociedade justa, equânime, igualitária”.

Ressalta-se que a ação profisssional do pedagogo pautado na ética tem respaldo legal ao especificar que;

O exercício da profissão de Pedagogo pautar-se-á: a. no respeito, na dignidade e na integridade do ser humano, objetivando o desenvolvimento harmônico do Ser e dos seus valores, munindo-se de técnicas adequadas, assegurando os resultados propostos e a qualidade satisfatória da educação; b. na defesa da democracia, respeitando as posições filosóficas, políticas, religiosas e culturais, analisando crítica e historicamente a realidade em que atua, buscando a socialização do saber; c. na promoção do bem-estar do indivíduo e da comunidade atuando a favor destes com aplicação de várias áreas do conhecimento humano, selecionando métodos, técnicas e práticas que possibilitem a consecução do ato de educar; d. na responsabilidade profissional através de um constante 
desenvolvimento pessoal, cientifico, técnico e ético (BRASIL, 2009, p. 1).

Esses fundamentos legais para o pedagogo se interligam e exemplificam a ética do pedagogo em qualquer espaço, tanto em escolas como em espações não escolares. Portanto, entende-se que a transparência, a valorização dos sujeitos, a promoção do bem-estar, respeitando e valorizando a cultura e sem perder de vista o saber científico, que norteia as ações deste profissional são primordiais para que o resultado das ações delineadas contribua para atender as demandas da instituição. Foi com esses pressupostos que a ação educativa foi realizada na Universidade Autônoma San Sebastian (UASS).

\section{A Experiência em Pedagogia Empresarial}

O contexto e organização da experiência da ação educativa em espaço não escolar foi a Universidade Autônoma San Sebastian (UASS), localizada na zona urbana central, na cidade Pedro Juan Caballero/Departamento de Amambay - Paraguai. Essa instituição oferta o curso de Medicina, tendo diferentes turmas do primeiro ao quinto ano. É habilitada sob a Lei 3.185 de 2006, fundada em fevereiro de 2015.

No que diz respeito à Gestão da Universidade, é composta por: "Decano" Diretora Geral, Assessora Geral, Diretor Acadêmico, Coordenadora Pedagógica, Diretor Financeiro, funcionários do Departamento financeiro, professores, uma caixa, Diretor e Assistente de Marketing, uma secretária acadêmica e assistentes de secretaria, Psicóloga, Bibliotecária, motorista e auxiliares de serviços diversos.
A Universidade central da UASS fica em Assunção, Capital do Paraguai é habilitada para ter mais de 52 cursos. Em Pedro Juan Caballero, seu público - alvo são $90 \%$ de brasileiros oriundos dos diferentes estados do Brasil, além de estudantes da Bolívia e Argentina que fazem transferência para esta instituição.

A Universidade comporta hoje mais de 800 acadêmicos regularmente matriculados. Com vários professores, formados exclusivamente em Medicina nos países: Paraguai, Brasil, Bolívia, Argentina, Cuba.

No que diz respeito à caracterização da estrutura física, possui salas de aula, laboratórios, biblioteca, sala de xérox, sala de atendimento psicológico, restaurante e cantina universitária, uma secretaria acadêmica, uma sala da Coordenação e Direção Pedagógica, uma sala de Assessoria Geral, uma sala do departamento financeiro, uma sala para atendimento financeiro, uma sala da Direção Geral da Universidade.

A experiência da ação educativa na área da pedagogia empresarial, realizada nesta instituição, incluiu a análise das necessidades institucional, especificamente, relacionada a melhoria na gestão e organização dos recursos humanos e outras ações para atender as demandas observadas. Por isso, teve o objetivo geral de contribuir com a elaboração do manual de funções dos departamentos da instituição, com respaldo do Regulamento Geral da Universidade; e possibilitar qualificação aos funcionários sobre a utilização do Sistema Informático Acadêmico por meio de um seminário. Além deste, teve os seguintes objetivos específico: ler o regulamento Geral da Universidade Autônoma San Sebastian; construir o 
Manual de funções nos departamentos da instituição; estudar as reais funções da Secretaria Acadêmica; analisar e acompanhar as funções dos funcionários da secretaria acadêmica; fazer um Seminário para qualificar a equipe de funcionários.

É importante lembrar que incialmente, aconteceu a visita técnica na instituição (UASS), a fim de manifestar o interesse para desenvolver o Plano de Intervenção, no sentido de contribuir com o atendimento das demandas/necessidades da instituição. Com isso, em reunião com o Diretor Acadêmico, foi sugerido à construção de manual de organização/função de cada departamento da instituição, especialmente, na secretaria acadêmica com suporte do Regulamento Geral da Universidade. Outra proposta sugestão do diretor refere-se a pesquisa com os acadêmicos do Curso de Medicina, com o objetivo de avaliar a prática pedagógica dos professores e ressaltou que esta pesquisa proporcionará informações para detectar pontos fortes e necessidades de melhorias do trabalho docente.

A sequência para a realização das incluiu cinco momentos, que abrangeu leituras e estudos dos documentos oficiais da Instituição, bem como a realização de ações práticas. Para melhor compreender os momentos desta ação educativa, explicitamos abaixo:

No primeiro dia: realizou-se leitura do Regulamento Geral da Universidade Autônoma San Sebastian. Essa ação foi necessária para ter conhecimento de como se organiza/funciona cada departamento desta instituição. Além disto, conheceu e analisou o sistema informático da
Universidade (“Gestión Educativa de la UASS"), pois nele, são realizados todos os procedimentos acadêmicos e financeiros dos matriculados na instituição.

É fundamental frisar que a leitura realizada foi importante, pois foi possível conhecer o lócus, como se organiza a instituição, quais os objetivos, quem são o público-alvo para adentramos na realidade e compreender as suas reais necessidades.

No segundo dia: foi realizado a leitura das reais funções da Secretaria Acadêmica. Entender a dinâmica desse setor possibilitou pensar melhoria desta função para atender de maneira eficiente os acadêmicos desta Insituição de Ensino Superior.

No terceiro dia: análise e acompanhamento das funções dos funcionários da secretaria acadêmica: Para dar sequência, analisou-se sob supervisão da Assessora Geral da Universidade e Orientadora do Estágio de que forma são as atividades párticas dos funcionários. Cabe destacar que a Assessora Geral da Universidade, desempenha um papel relevante, pois neste setor envolve o gerenciamento de toda instituição, requer conhecimentos construídos ao longo de sua formação, incluindo os saberes ligados a Economia e Administração e especializações em Supervisão e Controladoria. Esse setor acompanha, supervisiona, registra, avalia, elabora e reelabora as atividades e ou atribuições inerentes aos departamentos da instituição para melhorar e provocar mudanças de comportamentos de forma positiva, com o intuito de melhorar a qualidade e otimizar o trabalho 
empresarial e favorecer excelência no atendimento ao público-alvo.

As atividades que foram realizadas nos três primeiros dias possibilitaram conher esse contexto profissional, incluindo os documentos legais, as funções e os profissionais da secretária acadêmica que foram os principais participantes da intervenção. Esses procedimentos vão ao encontro de Pasa e Nogaro (2010, p. 160) ao pontuarem que

para atuar na empresa, o pedagogo precisa ser pesquisador, empreendedor e criativo. É necessário ter conhecimento da empresa, de sua organização, saber como é e funciona a visão administrativa, pois atende as pessoas num contexto bem específico: o do seu trabalho. Ele precisa circular por toda a organização, o que exige alta performance nas relações interpessoais, integração à corporação, conhecer os valores que a sustentam.

No quarto dia: construção do Manual de Funções que inicio após a leitura do Regulamento institucional e foi construído o Manual sistemático e informativo com suporte das informações legais dos Documentos Oficiais.

Lembra-se que o manual em questão, é relevante para a Gestão da instituição (Direção, Coordenção, funcionários dos departamentos: acadêmico e financeiro), uma vez que disponibiliza de maneira didática informações acerca dos procedimentos corretos e seguros para efetivação da inserção do cadastro digital do acadêmico que se matricular na Universidade. Além disso, tem por objetivo, nortear, mediar e dar suporte de forma sistemática, com o propósito de suprir as dúvidas e evitar possíveis erros que geram transtornos e duplicação de informação.

No quinto dia: elaboração de Seminário a fim de possibilitar qualificação sobre a utilização do Sistema Acadêmico. Foram apresentados os procedimentos corretos para efetivação dos seguintes serviços: Pré-matrícula, matrícula, atualização de dados cadastrais dos acadêmicos. E também quanto aos procedimentos financeiros, como por exemplo: emissão de contrato financeiro, ajustes de mensalidades do curso de Medicina.

Essas ações possibilitaram penar nas ações e contribuições do pedagogo em espaços não escolares, especificamente, em organizações. Assim, é possível sugerir que esse profissional poderá trabalhar com análise da instituição, pensar em estratégias e técnicas $\mathrm{s}$ para melhorar a organização das atividades profissionais. Em consonância com essa intervenção que incluiu um conjunto de procedimentos com o suporte de materiais organizacionais e tecnológicos, explicitamos melhor o quão é crucial a colaboração do Pedagogo Empersarial, como destaca Andrade Filho (2006, p, 8):

\begin{abstract}
A inserção dos 'pedagogos empresariais' no mercado de trabalho tende apreparar este profissional para atuar na área empresarial e desenvolver habilidades humanas e técnicas com vistas à compreensão das transformações provocadas pelos avanços das ciências e das novas tecnologias. Esta, acapacidade de se perceber a educação continuada como poder de 'inovar ereinventar' o perfil do pedagogo brasileiro para enfrentar e ampliar o novo mercado de trabalho na atual sociedade informatizada.
\end{abstract}

E no que diz respeito à sistematização, ao planejamento, acompanhamento e orientação às 
funções dos funcionários, corroboramos com

Pascoal (2007), que detalha as principais funções do Pedagogo nesses espaços não escolares (Empresas):

As funções e atribuições do Pedagogo dentro da empresa relacionam-se a cinco campos: atividades pedagógicas, técnicas, sociais, burocráticas e administrativas, podendo ser assim sintetizadas: conceber, planejar, desenvolver e administrar atividades relacionadas à educação na empresa; diagnosticar a realidade institucional; elaborar e desenvolver projetos, buscando conhecimento também em outras áreas profissionais; coordenar a atualização em serviço dos profissionais da empresa; planejar, controlar e avaliar o desempenho profissional dos funcionários da empresa;assessorar as empresas no que se refere ao entendimento dos assuntos pedagógicos atuais (PASCOAL, 2007, p. 190).

Neste viés é imprescindível mencionar que o Pedagogo Empresarial necessita exercer as atividades propostas com ética e transparência, com o intuito de contribuir com o processo de desenvolvimento da empresa, propondo a resolução de conflitos, demandas, e cooperar com o fortalecimento de vínculos na equipe para atingir os objetivos da instituição/organização e possibilitar a manuntençaõ da saúde do trabalhador.

No contexto desta organização de ensino superior o pedagogo contribuiu com a elaboração e execução de manuais de função dos diferentes departamentos empresariais. Além disso, preparou os funcionários, qualificando-os para para uso desses instrument diadático que, possivelemnete, irá ajudar na realização de suas atividades diárias.

\section{CONSIDERAÇÕES FINAIS}

Diante do exposto, é possível perceber que o pedagogo empresarial contribui significativamente, transformando, criando, recriando possibilidades para melhoria da organização e pessoas que transitam nelas, seja na função de profissional ou de cliente. E é possível quando o pedagogo buaca incialmente conhecer a instituição, a partir do conhecimento do contexto, ancorado na realidade e equipe de funcionários da empresa pode pensar no projeto de intervenção e na execução do mesmo.

Através de projeto de intervenção é possível que os participantes sejam participativos e autônomos. E na presente intervenção, os profissionais receberam uma mediação com respaldo do Regulamento Geral da Instituição, com intuito de desenvolver as funções da melhor maneira possível. Com isso, houve melhorias na organização que atendeu ao propósito de suprir as necessidades em prol de um atendimento de qualidade aos acadêmicos, professores dentre outros que utilizam do serviço da Universidade Autônoma San Sebastian (UASS), na cidade Pedro Juan Caballero/Paraguai.

\section{REFERÊNCIAS}

\section{ANDRADE FILHO, F. A. de. Filosofia e epistemologia: gestão do conhecimento e Pedagogia Empresarial na sociedade informatizada. Disponível}

em:http://www.users.hotlink.com.br/fico/refl0091.ht m. Acesso em: 26 dez. 2017.

AUNIPEDAG.BR, Associação Universitária de Pedagogia do Brasil. Código de Ética do profissional pedagogo. Disponível em: http://www.tiberiogeo.com.br/texto/CodigoEticaPeda gogo.pdf. Acesso: 30 de jul 2017. 
BRASIL. Ministério da Educação. Diretrizes Curriculares Nacionais para os Cursos de Pedagogia. Parecer CP/CNE 05_2005, homologação publicada no DOU 15/05/2006, Seção 1, p. 10. Parecer CP/CNE 03_2006, homologação publicada no DOU 11/04/2006, Seção 1, p. 19. Resolução CP/CNE 01/2006, publicada no DOU 16/05/2006, Seção 1, p. 11.

GONH, Maria da Glória. Educação Não Formal, Aprendizagens e Saberes em Processos

Participativos. Investigar em Educação - II ${ }^{\text {a }}$

Série, Número 1, 2014.

GONÇALVES, Roseli.

A Pedagogia Empresarial e as Praticas

Pedagogicas dentro da Empresa Disponível em: http://www.webartigos.com./artigos/a -pedagogia-empresarial-e-as-praticas -dentro-da-empresa/14896/Acesso em: 26 de dez. 2017.

PASA, Bethânia; NOGARO, Arnaldo. A responsabilidade da Pedagogia e do Pedagogo (empresarial) frente à crise ética e humana. REP Revista Espaço Pedagógico, v. 17, n. 1, Passo Fundo, p. 154-166, jan./jun. 201

PASCOAL, Mirian. O Pedagogo na Empresa. Disponível em: https://periodicos.pucpr.br/index.php/dialogoeduc acional/article/viewFile/4207/4126. Acesso: 26 de dez. 2017.

PRADO, André Alves. A Atuação do Pedagogo na Empresa: A Aplicação Eficiente e Eficaz da Pedagogia Empresarial. Disponível em:

file:///E:/7\%\%20semestre\%20Pedagogia/Educação \%20em\%20Espaços\%20não\%20escolares/REFE RÊNCIAL\%20TEÓRICO/4.2\%20A\%20Atuação $\% 20$ do $\% 20$ Pedagogo $\% 20$ na $\% 20$ Empresa $\% 20 \% 2$ 0A\%20Aplicação.pdf. Acesso: 30 de jul 2017.

SIMSON, Olga R. de M. von; PARK, Margareth B.; FERNANDES, Renata S.. Educação nãoformal: um conceito em movimento. IN: Visões Plurais, conversas plurais. São Paulo: Itaú Cultural, 2007.p.13-41

QUIRINO, R. Saberes do Pedagogo para a Prática Educativa nas Organizações Empresariais. Belo Horizonte: Dissertação (Mestrado) Centro Federal de Educação Tecnológica de Minas Gerais - CEFET-MG, 2005. Disponível em:
http://www.et.cefetmg.br/info/downloads/Raqu el\%20Quirino.pdf . Acesso em 26 de dez. 2017.

\section{Endereço para correspondência:}

Gustavo Enrique Costa

Rua Poconé, n.11, Cohab - Ponta Porã-MS

E-mail: gustavo.pedagogia.ufms@gmail.com

\section{Como citar este artigo (Formato ABNT):}

COSTA, Gustavo Enrique; ALCANTARA, Doralice Nunes. Ação educativa a partir da pedagogia empresarial numa universidade paraguaia. Educação, Psicologia e Interfaces, vol.1, n.2, p. 5-13, 2017. DOI:

https://doi.org/10.37444/issn-2594-5343.v1i2.43

Recebido: 04/10/2017.

Aceito: 26/12/2017. 